\title{
Tele-Genetics: Using Low Cost Internet Technology to Provide Genetic Consultations to Rural Areas in Sri Lanka
}

Dr. V.H.W Dissanayake MBBS, PhD

Senior Lecturer and Medical Geneticist

\section{Nisansala}

Genetic Nurse

\section{Dr. S. Sandamal MBBS}

Research Assistant

Prof. R.W. Jayasekara MBBS, MIBiol(UK), CBiol(UK), PhD.

Director and Medical Geneticist

Human Genetics Unit, Faculty of Medicine, University of Colombo, Kynsey Road, Colombo 8, Sri Lanka.

E-mail address: Dr. V.H.W. Dissanayake - vajirahwd@hotmail.com

URL http://www.hgucolombo.org

Sri Lanka Journal of Bio-Medical Informatics 2010;1(1):46-48

DOI: 10.4038/sljbmi.v1i1.1465

\begin{abstract}
Tele-medicine is still in its infancy in Sri Lanka and its implementation in the country has been slow due to high cost of infrastructure. Tele-genetics is a simple tele-medicine project implemented in June 2006 using low cost feely available technology and infrastructure aimed at taking clinical genetic services confided to Colombo to rural areas of Sri Lanka. We report here the implementation of this project and its successes and failures over the past two years.
\end{abstract}

Keywords: Tele-medicine, Genetic Services, Sri Lanka

\section{Background}

The specialty of medical genetics is still in its infancy in Sri Lanka. The Human Genetics Unit located in Colombo is the only specialised centre in the public sector providing medical genetic services including genetic evaluation, counselling and testing to the entire population of 20 million people. Those who require the services of the Human Genetics Unit have to travel to Colombo. In view of these logistical constraints, a solution to overcome this problem had to be found.

\section{Tele-Genetics}

In 2005 the government of Sri Lanka began establishing Internet Centres named 'Nanasalas' in many parts of the country to provide internet access to rural people. So far over 575 of these centres have been set up (http://www.nanasala.lk). We made use of the opportunity created by this endeavour and linked up with the 'Nanasala' network to offer on-line genetic consultations as a solution to the above mentioned problem.

The service involves the following steps:

1. When a patient is referred to the Human Genetics Unit, the patient or the relatives can contact a 'Nanasala' in his/her area and hands over the referral letter

2. The 'Nanasala' operator scans and emails the letter to us 
3. We give an appointment for the consultation

4. At the appointed time the patient arrives at the 'Nanasala' and the online link is established with us using Skype software which allows free video-conferencing

5. Following the consultation an e-mail letter is sent to the 'Nanasala' addressed to the referring physician

6. This e-mail is printed and given to the patient who takes it to the referring doctor.

7. If a blood sample has to be sent to the Human Genetics Unit for testing, it can be arranged by the 'Nanasala' using a local courier service.

8. Pre and post- test counselling is provided in such instances and appropriate referral letters are sent to the referring physicians via email through the Nanasala.

Skype software is freely available (http://www.skype.com). Skype does not charge for video conferencing between two points. Internet connectivity to 'Nanasalas' are funded by the government. The Human Genetics Unit does not charge for the consultation. The 'Nanasala' may however charge the patients for the services provided by them. The on-line real time video/audio link enables free interaction between the geneticist and the patient like in the case of a normal face to face consultation. A consultation in progress is shown in Figure 1.

Figure 1. A tele-genetics consultation in progress.

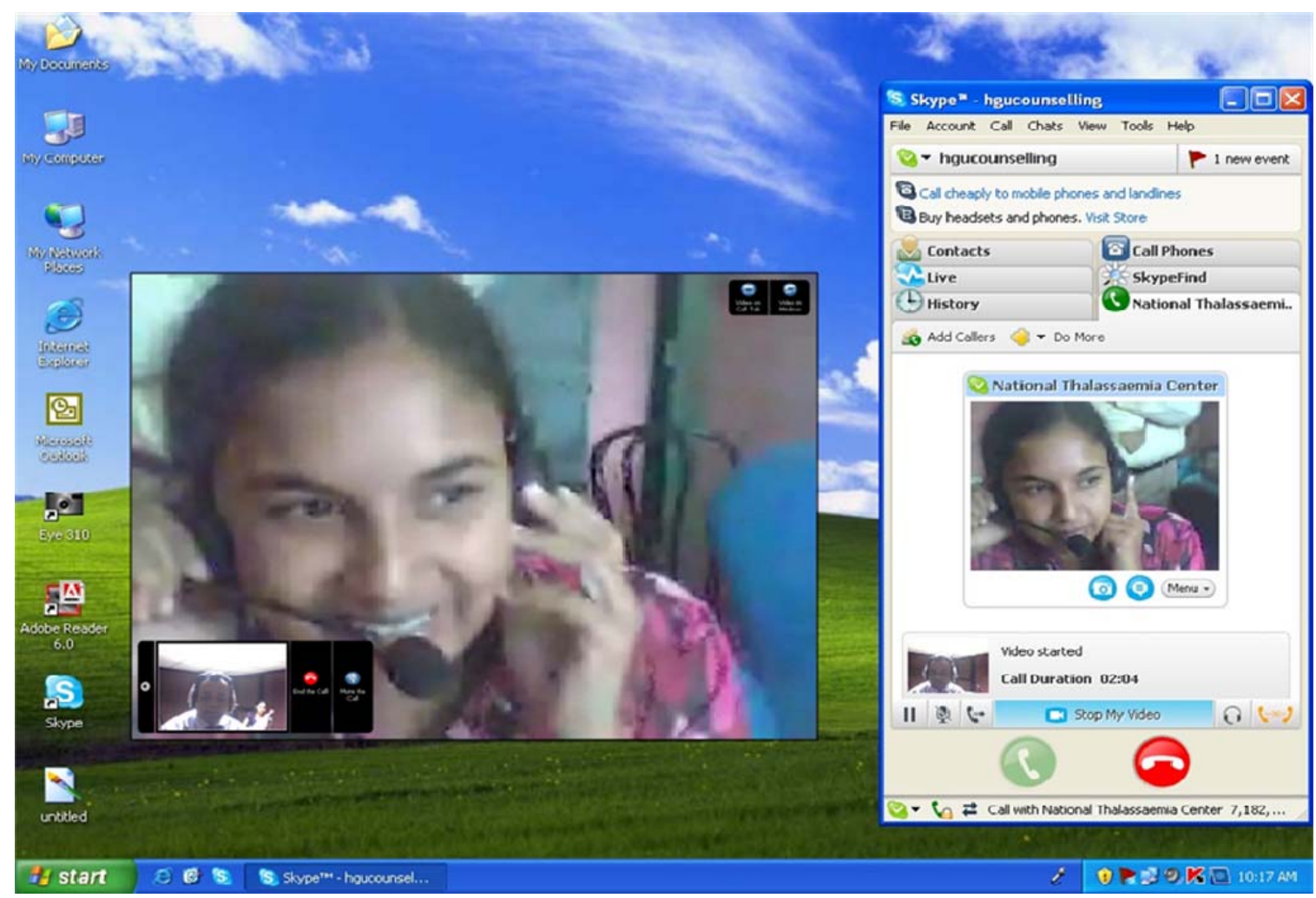

The service was launched on the 1 June 2007. Since then 40 consultations have taken place up to 30 November 2009. The location of Nanasalas which have made use of this service are mapped in Figure 2. In addition to free standing 'Nanasalas', a special link was established with the National Thalassaemia Centre at the Teaching Hospital in Kurunegala. This resulted in the establishment of the first and so far only 'Nanasala' in a hospital in Sri Lanka at the Teaching Hospital, Kurunegala in June 2007. The service has been popularised through the Nanasala News Letters and also by conducting workshops for 'Nanasala' operators. 
Figure 2. Location of Nanasalas that have made use of the tele-genetics service.

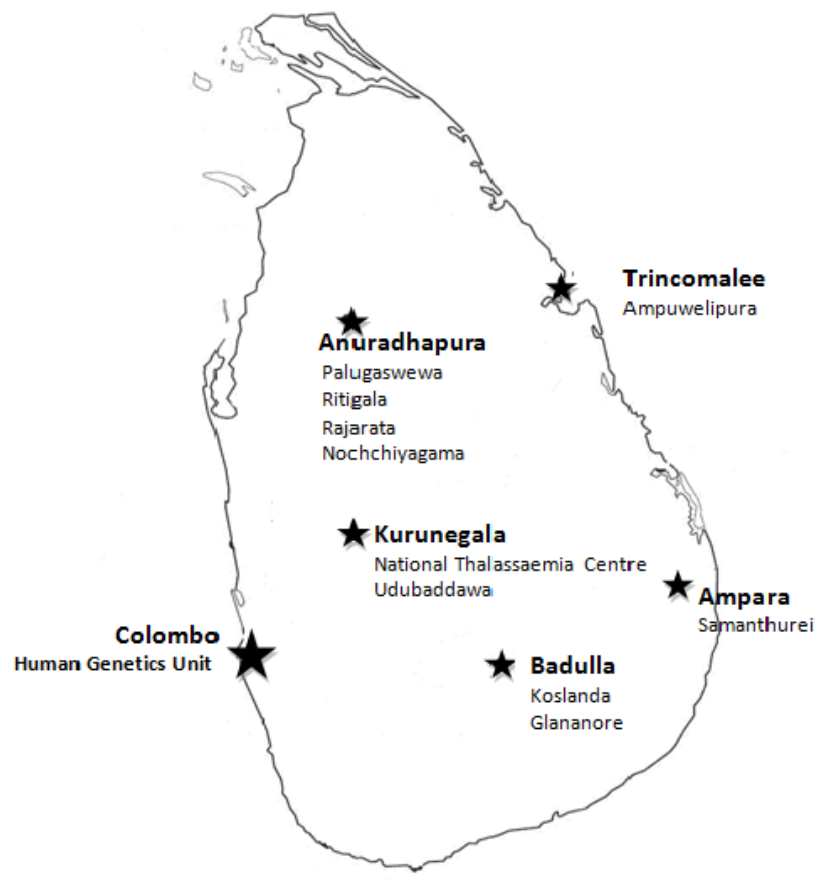

There are several drawbacks of this system as it exists at the present time. The impediments to conducting a successful service include poor internet connectivity in some parts of the country, lack of initiative on the part of the 'Nanasala' operators who find it challenging to create the suitable environment in their Nanasala's to provide consultations in a manner in which the privacy and confidentiality of the patient is maintained and patients with nongenetic problems being scheduled for consultations.

\section{Conclusions}

Tele-Genetics is now a routine part of the services provided by The Human Genetics Unit. It is a useful low cost model that can be easily implemented for remote areas that have Internet connectivity but do not have the services of medical geneticists. This is perhaps the case, not only in Sri Lanka but also in many parts of the world, especially in areas of the developing world.

\section{Acknowledgements}

This project received funding from the Information and Technology Agency of Sri Lanka (ICTA) under its Community Assistance Programme (ICTA/CON/73/C034). 